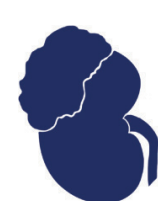

jkcvhl.com

KIDNEY CANCER: ORIGINAL ARTICLE

\title{
Bilateral Single-Stage Nephrectomy for Synchronous Bilateral Renal Cell Carcinoma
}

\author{
Ahmed Kotb ${ }^{1}$, Amer Alaref ${ }^{2}$, David Kisselgoff², Asmaa Ismail ${ }^{1}$, Radu Rozenberg ${ }^{2}$, Nishigandha \\ Burute $^{2}$, Walid Shahrour ${ }^{1}$, Owen Prowse ${ }^{1}$, Hazem Elmanasy ${ }^{1}$
}

${ }^{1}$ Urology Department, Thunder Bay Regional Health Science Centre, Northern Ontario School of Medicine, Thunder Bay, ON, Canada; ${ }^{2}$ Radiology Department, Thunder Bay Regional Health Science Centre, Northern Ontario School of Medicine, Thunder Bay, ON, Canada

\begin{abstract}
Bilateral synchronous renal cell carcinoma (RCC) is uncommonly encountered. Debate exists among urologists in managing these cases in a single surgery versus staged surgeries. We aim to report our experience in managing encountered cases using single-stage surgeries. Retrospective collection of cases with pathologically confirmed RCC that had single-stage bilateral renal surgery over the past 2 years. Three cases were identified. Patients were managed using bilateral transverse lateral lumbotomy. All patients did not have intraoperative or postoperative complications. Kidney function stayed stable after surgery. Single-stage bilateral renal surgery is a safe procedure. Bilateral transverse lateral lumbotomy allows for a fast and safe surgery with minimal complications. There is a possible histological dis-concordance in bilateral synchronous RCC.
\end{abstract}

Keywords: RCC, Lumbotomy, nephrectomy

Received: July 12, 2020; Accepted after revision: January 14, 2021; Published: January 25, 2021

Author for correspondence: Ahmed Kotb, MD, PhD, FRCS Urol, FEBU, Assistant Professor, NOSM, TBRHSC. 980 Oliver Road, Thunder Bay, P7B 6V4, ON, Canada. Phone: +1 807-285-9292. Email: drahmedfali@gmail.com

How to cite: Kotb A et al. Bilateral single-stage nephrectomy for synchronous bilateral renal cell carcinoma. J Kidney Cancer VHL. 2021; 8(1): 7-11

Doi: https://doi.org/10.15586/jkcvhl.v8i1.151

Copyright: Kotb A et al.

License: This open access article is licensed under Creative Commons Attribution 4.0 International (CC BY 4.0). http://creativecommons.org/ licenses/by/4.0

\section{Introduction}

The incidence of most cancers is on the rise. Canadian cancer statistics was expecting 7500 new kidney cancer diagnosis within 2020 with an age standardized incidence rate of 17.3 in 100,000 population, with Ontario expected to have onethird of the newly diagnosed cases (1). Bilateral renal cell carcinoma (RCC) occurs in less than $5 \%$ of kidney cancer, with the incidence of synchronous bilateral RCC being 1 out of $333(0.3 \%)$ patients with RCC (2).
The aim of our work was to present our experience in managing synchronous bilateral RCC using single-stage bilateral transverse lateral lumbotomy incision.

\section{Methods}

Retrospective data analysis of patients having synchronous bilateral clinically suspected RCC, which was managed by single-stage surgery by a single urologist (AK), was the 
method of choice. The urologist performing the surgery had 15 years' experience in performing renal cancer surgery. Data collection included information on patients' age, sex and clinical presentation, preoperative eGFR and images, pathological analysis, and postoperative eGFR. All cases included in the study were managed by open surgery. All had single-stage bilateral transverse lateral lumbotomy incision, an approach we published last year (3). During surgery, the patient is positioned with the side of surgery elevated to 45 degree. An upward smiling incision subcostal and running parallel to the costal margin is done. Direct adequate access to the kidney could be done without the need for extensive diaphragmatic dissection. Full mobilization of the kidney and renal pedicle is done. The tumor is then identified and marked all around, few millimeters away from the tumor edge with cautery. We then clamp the pedicle and complete the surgery under warm ischemia. All patients had their first postoperative computed tomography scan 12 months post-surgery. Our study included only patients that had single-stage bilateral renal surgery. Institutional ethical approval as well as patients' consent to be included in the study was obtained.

\section{Results}

We could identify three patients managed by single-stage bilateral renal surgery for clinically suspected RCC. All three patients were men with a median age of 76 years. They had their cancer diagnosed accidentally without symptoms suggestive of renal tumor.

The first patient was 78 years old and was being followed by the vascular surgery team for a large abdominal aortic aneurysm (AAA), with bilateral enhancing renal masses diagnosed at the time of angiography. The right kidney had a single mass while the left kidney had multifocal tumors. The patient had single-stage left radical nephrectomy (RN) and right partial nephrectomy (PN). Pathology showed right clear-cell RCC (ccRCC) and left papillary RCC (pRCC) with negative margins. His eGFR was stable at 14 months after surgery and a new scan 1-year post surgery confirmed no cancer recurrence. Figure 1 shows the bilateral renal tumor, AAA, and a postoperative scan.

The second patient was 76 years old with a history of left open PN for ccRCC and a negative margin done 5 years ago. CT scan performed as part of postoperative surveillance diagnosed a suspected suspicious renal tumor with the left side being at the same area as that of the previous PN. Bilateral PN could be successfully done in a single stage. Pathology confirmed bilateral ccRCC, with negative margins. eGFR is stable at 12 months post-surgery. Figure 2 shows the bilateral renal tumors.

The third patient was 63 years old. He initially had a right enhanced renal mass $(1.5 \mathrm{~cm})$, accidentally diagnosed

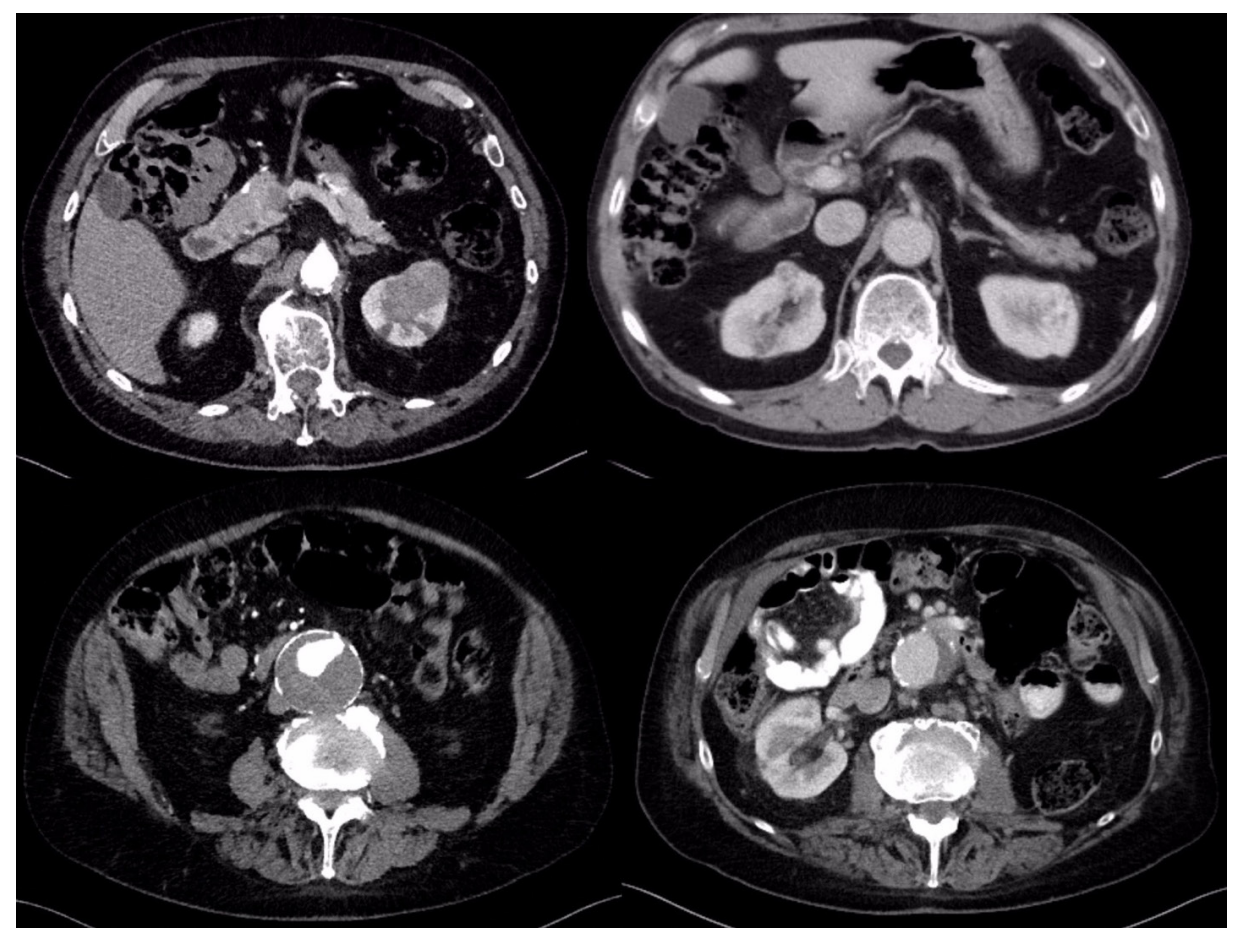

Figure 1: First patient: preoperative bilateral renal tumor, large AAA, and 14 months' postoperative image showing no recurrence. 


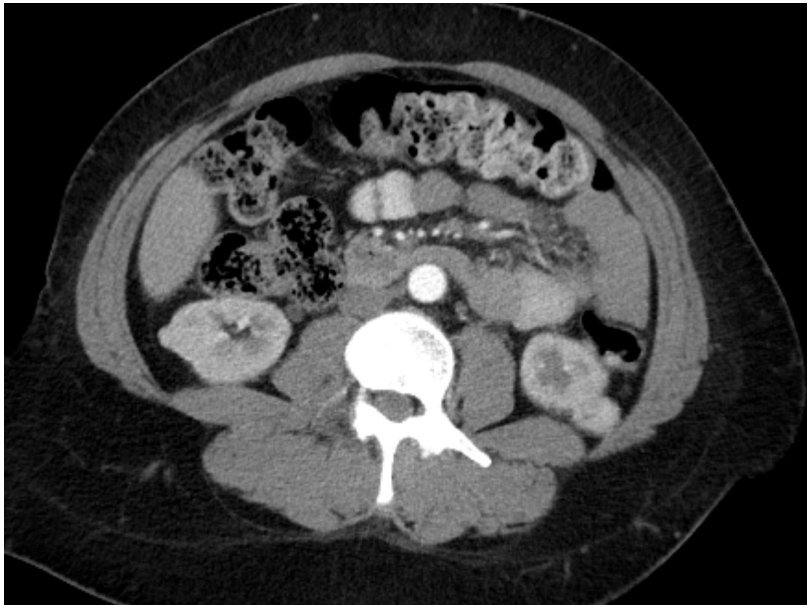

Figure 2: Second patient: bilateral renal tumor.

following an ultrasound for a vague abdominal pain. He elected for surveillance, and CT done after 1 year showed a stable right renal tumor and a new left renal tumor. Single-stage bilateral PN was done. Pathology showed bilateral ccRCC with negative margins. eGFR was stable at 12 months post-surgery. Figure 3 shows the bilateral renal tumors.

All PNs for these patients were stage T1a and were managed through single-stage bilateral transverse lateral lumbotomy. Our surgical approach has been presented in former publications $(3,4)$.

Warm ischemia was used for all cases undergoing PN and median warm ischemic time (WIT) was $10 \mathrm{~min}$ (4-16 min). The median surgical time was $120 \mathrm{~min}(90,180$, and $120 \mathrm{~min}$, respectively). No blood transfusion was required during surgery or the postoperative period. The median hospital stay was 3 days $(5,3$, and 2 days, respectively). We did not have any grade 3 or higher Clavien grade complications in the three patients. Table 1 summarizes patients' clinical and pathological outcomes.

\section{Discussion}

Bilateral renal malignancy is infrequently encountered and the choice of single stage versus staged bilateral renal surgery is debatable and usually left to the preference of the operating surgeon. Single-stage bilateral renal surgery carries the benefit of a single anesthetic exposure in these patients with possible associated morbidities, but it is usually feared because of the anticipated higher risk of complications. Mason et al. (5) conducted a retrospective study on 76 patients who underwent single-stage bilateral PN over a period of 39 years and confirmed the safety of synchronous bilateral renal surgery, albeit with a complication rate of $20 \%$. In this study,

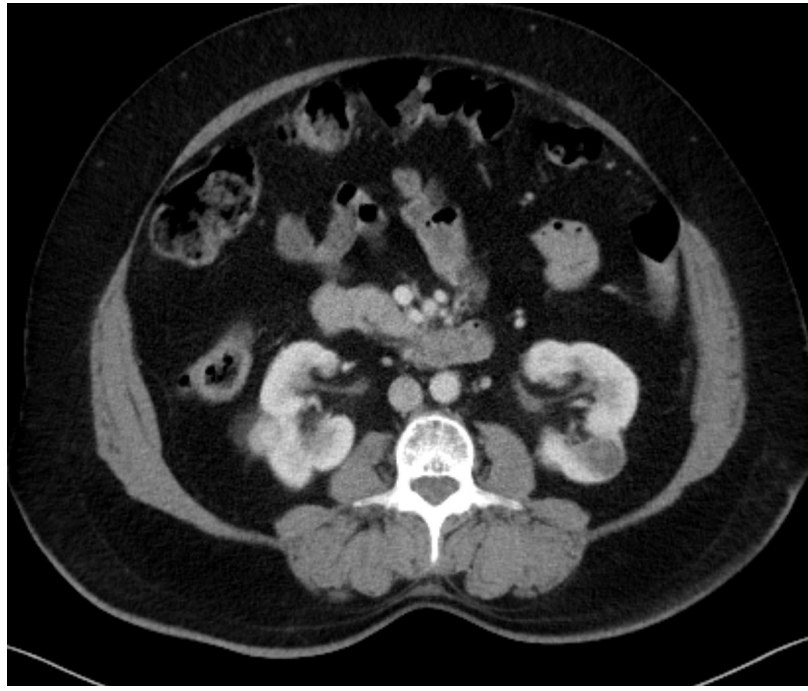

Figure 3: Third patient: bilateral renal tumor.

open surgery was performed, but the exact approach was not provided. On the other hand, Wang et al. (6) studied four patients managed by single-stage bilateral retroperitoneoscopic surgeries for renal tumors over a period of 6 years and found that four patients developed acute renal insufficiency and recommended staged surgeries rather than single stage for patients with bilateral renal tumors.

All our patients were managed through single-stage bilateral open retroperitoneal surgery through the transverse lateral lumbotomy incision. Our approach allowed easy direct access to the kidney and the renal pedicle, without the risk of pleural injury and by avoiding unnecessary exposure of the intraperitoneal organs. We usually start with the side having the larger or more difficult tumor, dissect the whole kidney and the pedicle, mark the area of resection around the tumor with cautery, and then apply warm ischemia. After removing the tumor and repairing the collecting system, we take few deep transverse mattress sutures to stop bleeding, then unclamp the pedicle and continue with renorrhaphy. We keep blood loss and WIT to the minimal, so as to avoid the risk of acute kidney injury. As our approach is subcostal, pain is well managed, better than the conventional supracostal approach, and the power of breathing is not affected in bilateral surgery as it avoids the extensive diaphragmatic dissection associated with the conventional open retroperitoneal approach. We could not identify studies that looked specifically at patients with Von Hippel-Lindau syndrome, but as renal tumors associated with this syndrome tend to grow faster, single-stage bilateral surgery should be considered whenever feasible.

Renal biopsy is generally not recommended for enhanced renal mass before surgery, unless some other pathology is 
Table 1: Summary of patients' clinical and pathological outcomes.

\begin{tabular}{|c|c|c|c|c|}
\hline & First patient & Second patient & Third patient \\
\hline \multicolumn{2}{|l|}{ Sex } & Male & Male & Male \\
\hline \multicolumn{2}{|l|}{ Age } & 78 & 76 & 63 \\
\hline \multicolumn{2}{|c|}{ Previous kidney surgery } & No & Yes & No \\
\hline \multicolumn{2}{|l|}{ Surgical approach } & $\begin{array}{l}\text { Bilateral transverse } \\
\text { lateral lumbotomy }\end{array}$ & $\begin{array}{l}\text { Bilateral transverse } \\
\text { lateral lumbotomy }\end{array}$ & $\begin{array}{l}\text { Bilateral transverse } \\
\text { lateral lumbotomy }\end{array}$ \\
\hline \multicolumn{2}{|l|}{ Surgery } & $\begin{array}{l}\text { Right PN } \\
\text { Left RN }\end{array}$ & Bilateral PN & Bilateral PN \\
\hline \multicolumn{2}{|c|}{ Total surgical time (minutes) } & 90 & 180 & 120 \\
\hline \multicolumn{2}{|c|}{ Total WIT (minutes) } & 4 & 16 & 10 \\
\hline \multicolumn{2}{|l|}{ Pathology } & ccRCC and pRCC & ccRCC & ccRCC \\
\hline \multicolumn{2}{|l|}{ Margins } & Negative & Negative & Negative \\
\hline \multirow[t]{2}{*}{ Tumor size $(\mathrm{cm})$} & Right & 1.5 & 2 & 1.5 \\
\hline & Left & Multiple (2, 3, and 3) & 2.5 & 2 \\
\hline \multirow[t]{2}{*}{ Stage } & Right & Tla & T1a & T1a \\
\hline & Left & $\mathrm{T} 2$ & T1a & T1a \\
\hline \multirow[t]{2}{*}{ Fuhrman grade } & Right & 3 & 3 & 3 \\
\hline & Left & N/A & 4 & 2 \\
\hline \multicolumn{2}{|l|}{ Hospital stay } & 5 & 3 & 2 \\
\hline \multicolumn{2}{|c|}{ Preoperative eGFR } & 55 & 58 & 70 \\
\hline \multicolumn{2}{|c|}{ Postoperative eGFR } & 50 & 52 & 63 \\
\hline \multicolumn{2}{|c|}{ Clavien 3 or higher complication } & None & None & None \\
\hline \multicolumn{2}{|c|}{ Cancer recurrence in 1 year } & None & None & None \\
\hline
\end{tabular}

suspected or a minimally invasive intervention like radiofrequency ablation is planned. As our three patients elected for surgery and CT clearly showed enhanced heterogenous masses, surgery was directly planned.

Klatte et al. (7) conducted an international multicentric study from 12 urological centers studying 118 patients who presented with synchronous bilateral RCC. Half of the patients were managed through a single-stage bilateral surgery. The authors confirmed equal oncological and functional outcomes. They added that synchronous renal RCC tends to have a higher frequency of papillary histology than unilateral cases. A large review of the SEER database for patients with bilateral solid renal tumors found a malignant concordance rate of $99 \%$ and a histological concordance rate of $93 \%(8)$. In our series, one out of three patients had histological dis-concordance with clear-cell histology identified in one kidney and papillary histology in the other kidney. Arnoux et al. (9) found that ccRCC is associated with pRCC in $3 \%$ of cases.

Reddy et al. (10) reported grade 3 or higher complications in nearly $15 \%$ of their cases managed by $\mathrm{PN}$, mostly manifested in the form of urine leak or bleeding requiring exploration or embolization. We did not encounter these complications in any of the three patients.

The main limitation of our report is the less number of patients; however, this together with the available few other reports may confirm the safety of single-stage bilateral renal cancer surgery. Although Canadian urological association 
guidelines recommend first postoperative CT to be done at 24 months (11), we elected to do it at 12 months considering the possible higher risk of recurrence attributed to synchronous bilateral cancer. CT failed to identify any recurrent disease in all patients.

\section{Conclusion}

Single-stage bilateral renal surgery is a safe procedure in experienced hands. Bilateral transverse lateral lumbotomy allows for a fast and safe surgery with minimal complications. There is a possible histological dis-concordance in bilateral synchronous RCC.

\section{Conflict of interest}

Nothing to declare from all authors.

\section{References}

1. Brenner DR, Weir HK, Demers AA, Ellison LF, Louzado C, Shaw A, et al. Projected estimates of cancer in Canada in 2020. Can Med Assoc J. 2020 Mar 2;192(9):E199-205. https://doi. org/10.1503/cmaj.191292

2. Wiklund F, Tretli S, Choueiri TK, Signoretti S, Fall K, Adami HO. Risk of bilateral renal cell cancer. Ncol. 2009 Aug 10;27(23):3737-41. https://doi.org/10.1200/JCO.2008.20.6524

3. Ismail A, Oquendo F, Allard-Ihala E, Elmansy H, Shahrour W, Prowse $\mathrm{O}$, et al. Transverse lumbotomy for open partial/radical nephrectomy: How I do it. Urol Int. 2020;104(1-2):131-134. https://doi.org/10.1159/000504787

4. Kotb A, Ismail A, Elmansy H, Prowse O, Shahrour W. Spontaneous retroperitoneal hemorrhage in a patient with acquired cystic kidney disease. J Kidney Cancer VHL. 2020 Apr 16;7(1):1-4. https://doi.org/10.15586/jkcvhl.2020.123

5. Mason RJ, Atwell T, Lohse C, Bhindi B, Schmit G, Schmitz J, et al. Synchronous nephron-sparing approaches for bilateral renal masses: peri-operative and renal functional outcomes. BJU Int. 2018 Aug;122(2):243-8. https://doi.org/10.1111/bju.14221

6. Wang $\mathrm{B}$, Gong $\mathrm{H}$, Zhang $\mathrm{X}, \mathrm{Li} \mathrm{H}$, Ma X, Song E, et al. Bilateral synchronous sporadic renal cell carcinoma: Retroperitoneoscopic strategies and intermediate outcomes of 60 patients. PLoS One. 2016 May 2;11(5):e0154578. https://doi. org/10.1371/journal.pone.0154578

7. Klatte T, Wunderlich H, Patard JJ, Kleid MD, Lam JS, Junker $\mathrm{K}$, et al. Clinicopathological features and prognosis of synchronous bilateral renal cell carcinoma: An international multicentre experience. BJU Int. 2007 Jul;100(1):21-5. https:// doi.org/10.1111/j.1464-410X.2007.06877.x

8. Rothman J, Crispen PL, Wong YN, Al-Saleem T, Fox E, Uzzo RG. Pathologic concordance of sporadic synchronous bilateral renal masses. Urology. 2008 Jul;72(1):138-42. https:// doi.org/10.1016/j.urology.2008.01.043

9. Arnoux V, Fiard G, Descotes JL, Rambeaud JI, Long JA. Bilateral renal masses: Pathologic concordance and impact of temporal presentation. Minerva Urol Nefrol. 2012 Dec;64(4):287-93.

10. Reddy UD, Pillai R, Parker RA, Weston J, Burgess NA, Ho ET, et al. Prediction of complications after partial nephrectomy by RENAL nephrometry score. Ann R Coll Surg Engl. 2014 Sep;96(6):475-9. https://doi.org/10.1308/0035884 14X13946184903522

11. Kassouf W, Monteiro LL, Drachenberg DE, Fairey AS, Finelli A, Kapoor A, et al. Canadian Urological Association guideline for followup of patients after treatment of non-metastatic renal cell carcinoma. Can Urol Assoc J. 2018 Aug;12(8):231-8. https://doi.org/10.5489/cuaj.5462 